\title{
The natural history of pancreatic cancer in Manitoba: A population based study
}

JACK MARTIN, MD, FRCPC, BRIAN H WEINERMAN, MD, FRCPC

J MARTIN, BH WEINERMAN. The natural history of pancreatic cancer in Manitoba: A population based study. Can J Gastroenterol 1992;6(4):201204. Adenocarcinoma of the pancreas is a virulent malignancy. A retrospective study was undertaken to determine the natural history of the disease in Manitoba, and to examine which facets of the disease might predict survival. A retrospective review of the Manitoba Tumour Registry from January 1987 to December 1989 was performed. Two hundred and fourteen exocrine cases were identified, and known islet cell tumours, lymphomas and sarcomas were excluded. The variables analyzed were age, sex, surgical or radiological stage of disease, pathological differentiation, means of diagnosis and treatment. There were 112 females and 102 males with a median age of 73 years $(80 \%$ of patients were older than 60 years). The mean survival from time of diagnosis was only six weeks. Univariate analysis identified male sex, advanced stages and poor differentiation as poor prognostic indicators. Multivariate analysis revealed that advanced stage and lack of differentiation were independent prognostic variables. Treatment, which was very selective, was also noted on univariate analysis to be a prognostic indicator but was not used in the multivariate regression analysis. The poor prognosis of all individuals confirms the rationale of trying to develop better treatments for all stages of disease, and stage and pathological differentiation should be taken into account when designing clinical trials.

Key Words: Natural history, Pancreatic carcinoma

\section{Histoire naturelle du cancer du pancréas au Manitoba: Étude de population}

RÉSUMÉ: L'adénocarcinome du pancréas est un cancer relativement foudroyant. Une étude rétrospective fut entreprise pour déterminer l'histoire naturelle de cette maladie au Manitoba et pour en identifier les diverses facettes comme facteurs prédictifs du taux de survie. Une analyse rétrospective du Manitoba Tumor Registry de janvier 1987 à décembre 1989 a donc été entreprise. Deux cent quatorze cas de maladie exocrine ont été identifiés et les

Department of Medicine, St Boniface General Hospital, University of Manitoba and Manitoba Cancer Treatment and Research Foundation, Winnipeg, Manitoba

Correspondence and reprints: Dr Brian H Weinerman, Department of Medicine, St Boniface General Hospital, 409 Taché Avenue, Winnipeg, Manitoba R2H 2A6. Telephone (204) 237.2310

Received for publication January 25, 1992. Accepted June 9, 1992
A DENOCARCINOMA OF THE PAN. creas is a virulent malignancy with an extremely short survival, even in what appears to be locally invasive surgically resectable cases. From the 1900s to the 1970s, there has been a striking rise in the incidence and mortality from pancreatic cancer in both sexes (1). This increased incidence occurred in most European countries and in the United States (1), but seems to have plateaued in many countries for unknown reasons $(2,3)$, and has remained steady throughout the 1980s. Data from Cancer Statistics (Canada) for the first half of the 1980 s also show a remarkably constant number of about 2400 cases per year in this country (3). Disease distribution in Canada reveals a relative homogeneity of cases across the country with no obvious high or low incidence areas (3). It was thus considered that any figures derived for Manitoba should be representative for all of Canada.

There have been several epidemiological studies of pancreatic cancer, often combined with surgical approaches to identify important prognostic factors $(2,4-6)$. However, the present authors were about to perform a phase II drug study (Lederle) using survival as an endpoint. This study aimed to delineate carefully the natural history of pancreatic cancer in the population, in order to ascertain which factors may be important for prognosis and sur- 
nésidioblastomes, les lymphomes et les sarcomes furent exclus. Les variables analysées ont été : l'âge, le sexe, le stade chirurgical ou radiologique de la maladie, la différentiation pathologique, les techniques diagnostiques et le traitement. L'étude comportait 112 femmes et 102 hommes, dont l'âge moyen était de 73 ans ( $80 \%$ des patients avaient plus de 60 ans). La survie moyenne après le diagostic était d'environ six mois. Une analyse univariée a donné comme indicateurs du pronostic: les sujets de sexe masculin, le stade avancé de la maladie et une différentiation peu marquée. L'analyse multivariée quant à elle a révélé que le stade avancé de la maladie et l'absence de différentiation étaient des variables indépendantes du pronostic. Le traitement, qui fut très sélectif, fut également considéré parmi les indicateurs du pronostic dans l'analyse univariée mais ne fut pas utilisé dans l'analyse multivariée régressive. Le pronostic sombre pour tous les sujets justifie donc la recherche de meilleurs traitements pour toutes les étapes de la maladie. De même, la différentiation au plan de la pathologie et du stade de la maladie doit aussi entrer en ligne de compte lors de la modélisation des essais cliniques.

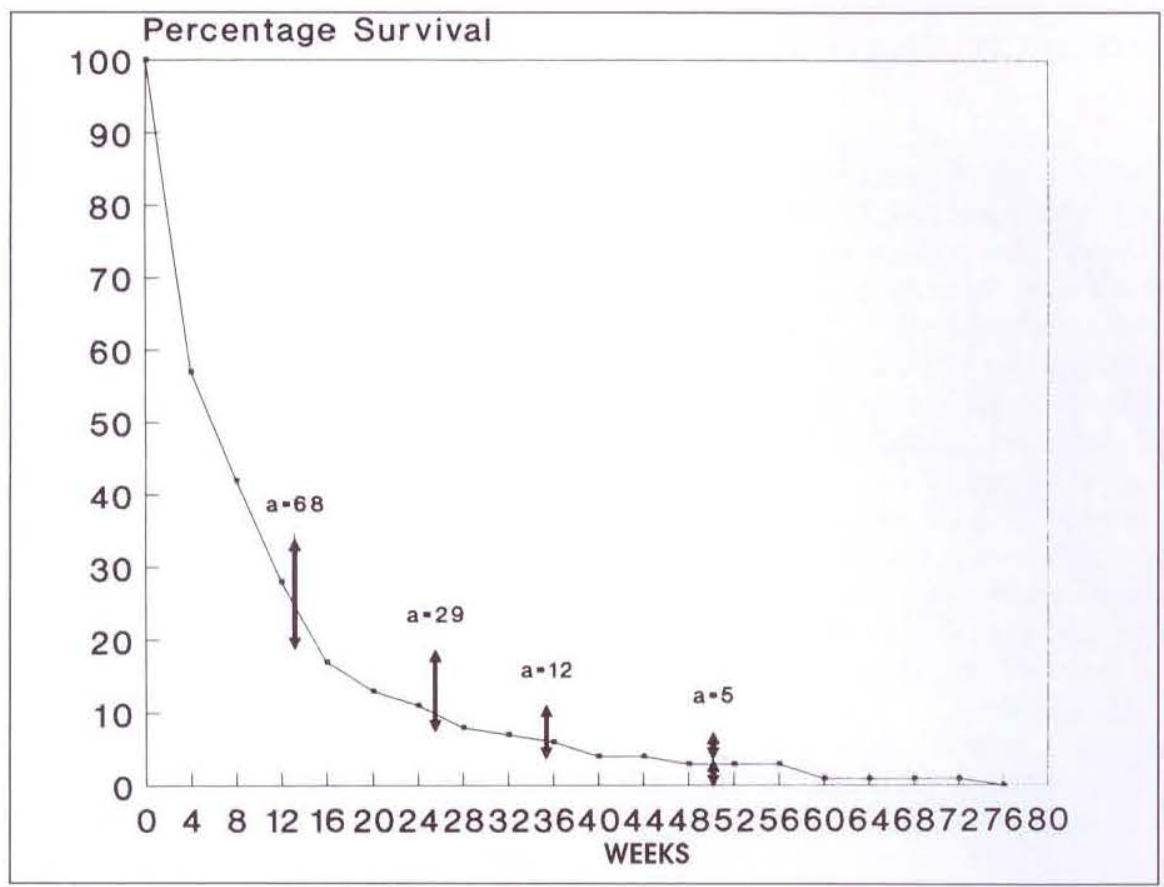

Figure 1) Pancreatic cancer survival of a series of 214 patients from the Manitoba Tumour Registry. a Alive; Arrows confidence limits vival. Patients from this population would also serve to construct a control group with the correct prognostic attributes to serve as a basis for comparison in the phase II survival investigation.

\section{PATIENTS AND METHODS}

The Manitoba Tumour Registry provided a three-year (January 1987 to December 1989) roster of 214 cases of all exocrine pancreatic carcinomas (biopsy, cytology or radiological). Known islet cell tumours, lymphomas and sarcomas were excluded from the analysis. No attempt was made to restrict entry, so that even individuals who were diagnosed at death were included in this analysis. The date of the diagnostic procedure (usually pathological but in some circumstances only radiological), was taken as the date of diagnosis. Histological or cytological diagnosis took precedence over radiological diagnosis, so that imaging techniques were only used for diagnosis if tissue or cytology was unavailable.

The date of diagnosis and last fol. low-up or death was recorded. The cases were analyzed for the following variables: age, sex, surgical or radiological stage of disease, pathological differentiation, means of diagnosis and treatment. Surgical and radiological stages were lumped together for the purposes of analysis as survival was not different according to either method of staging.

Survival plots were determined by the actuarial life-table method and were compared in a univariate analysis

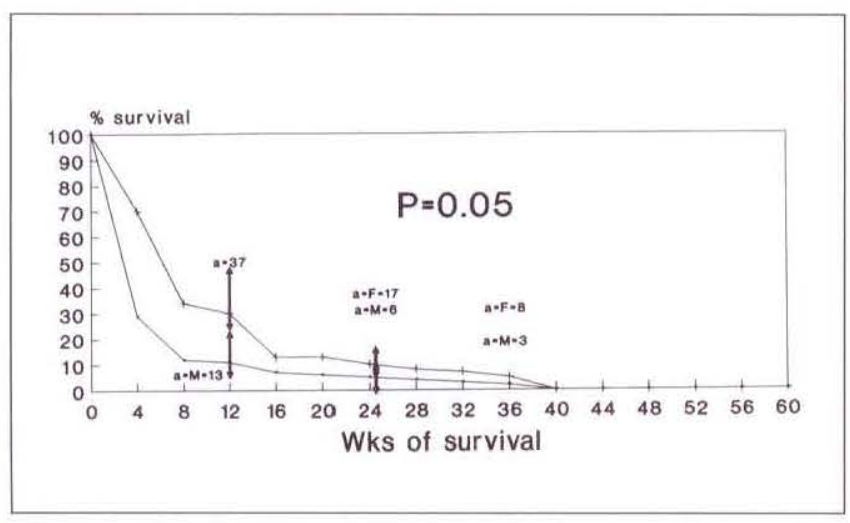

Figure 2) Survival of pancreatic cancer patients according to sex (112 females [+], 102 males [-] ). a Alive; F female; M Male; Arrows Confidence limits

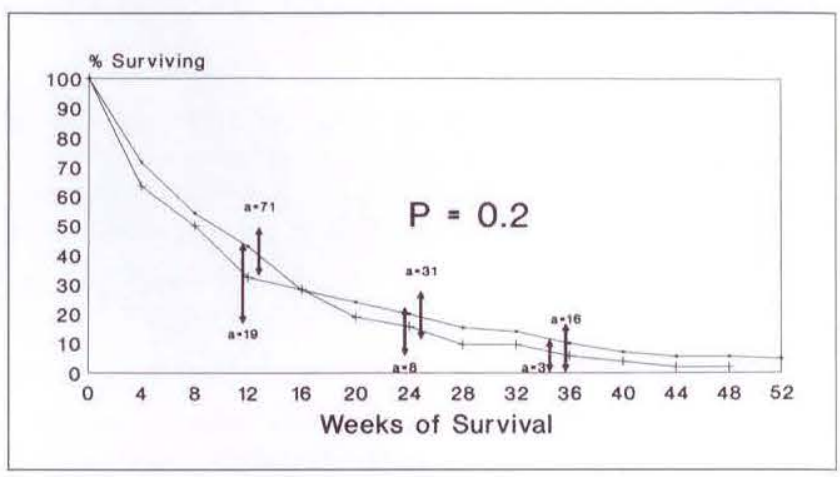

Figure 3) Survival of pancreatic cancer patients according to whether a tissue diagnosis was made ( 153 cases biopsy proven [\$]) versus diagnosis with an imaging procedure (61 cases no biopsy [ ]). a Alive; Arrows Confidence limits 


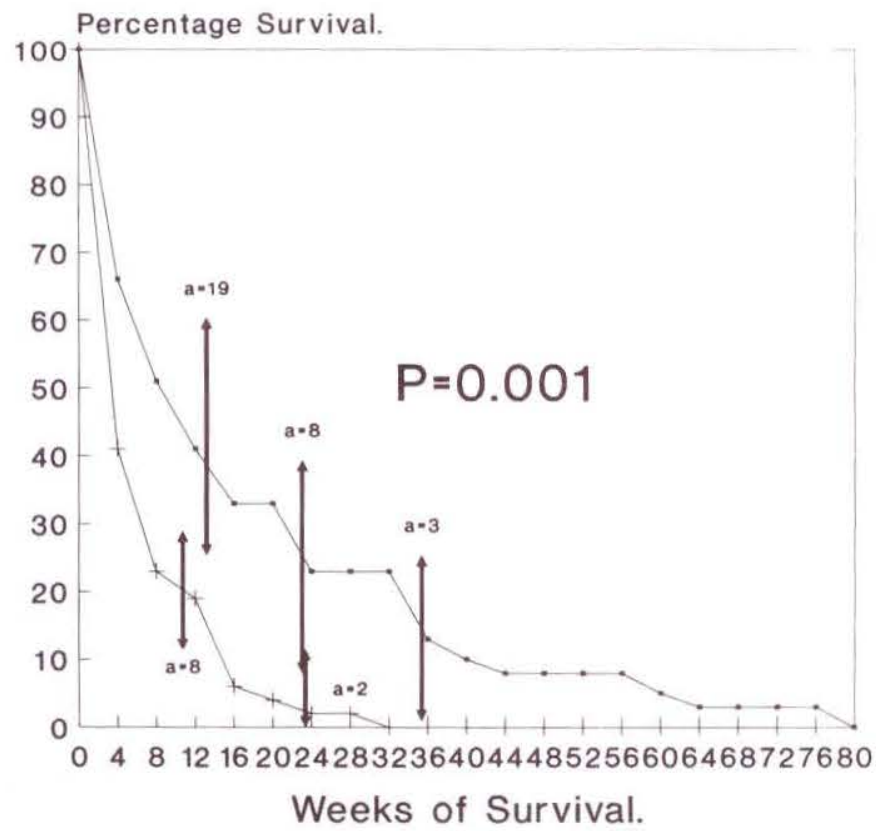

Figure 4) Survival of pancreatic cancer patients according to degree of differentiation ( 1 and 2: Well and moderately differentiated cancers, 39 cases[国] versus 3: poorly differentiated and anaplastic cancers, 47 cases [+]). A Alive; Arrows Confidence limits

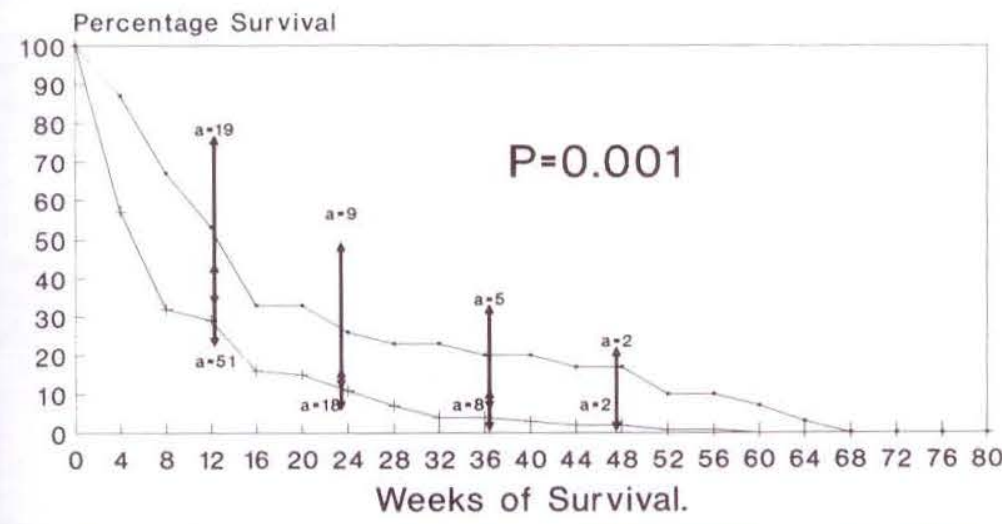

Figure 5) Pancreatic cancer survival according to stage of disease (stages 1 and 2,31 cases stages 3 and 4, 122 cases [+]), a Alive; Arrows Confidence limits

using log-rank Wilcoxan statistics. Multivariate regression analysis was performed on parameters which were significant on univariate analysis.

\section{RESULTS}

Two hundred and fourteen cases were provided, 112 females and 102 males, at variance with the usual sex distribution. The median age was 73 years (range 40 to 96). Eighty-eight per cent were over 60 years of age at diagnosis. The mean survival from time of diagnosis was only six weeks (Figure 1). The shortest survival was less than one week and the longest survivor lasted 78 weeks.

Univariate analysis was carried out using the variables mentioned. Age was not found to be a significant factor in survival. Female survival was slightly but significantly $(\mathrm{P}=0.05)$ greater than male survival (Figure 2). The median survival of females was 6.5 weeks compared with a median male survival of only three weeks.
TABLE 1

Staging of pancreatic cancer ${ }^{\star}$

Stage I No direct extension or regional lymph node involvement

Stage 2 Direct extension into adjacent tissue with no lymph node involvement

Stage 3 Regional lymph node involvement

Stage 4 Distant metastatic spread

- According to the American Joint Committee for Cancer staging and end results reporting

One hypothesis was that individuals who were diagnosed solely by radiological means would not actually have pancreatic cancer. Therefore, the authors wanted to measure the survival of the two groups (radiological diagnosis 61 cases and pathological diagnosis 153 cases), believing that those with a radiological diagnosis would survive longer (as some of the individuals might have benign disease, pancreatitis, etc). However, there was no significant difference in the survival of patients with a tissue diagnosis from those diagnosed by imaging procedures (Figure 3).

The authors also wished to examine whether patients with more poorly differentiated tumours had poorer survival than those who appeared to have lower grade characteristics, as viewed by the interpreting pathologist. No attempt was made to review all the pathological tissue. Not all submitted specimens had been graded as to cellular differentiation. In those that were ( 88 cases) (Figure 4), patients with some degree of differentiation (39 cases were well, or moderately differentiated) outlived those with poorly differentiated or anaplastic tumours (47 cases) $(\mathrm{P}=0.001)$. The other cases either had not been biopsied (61 cases) or no gradation of the cancer was reported (67 cases).

Staging was assigned according to the American Joint Committee for Cancer Staging and End Results Reporting (1), (Table 1). In patients for whom assigning the stage from the information was possible (only two of 214 were stage 1), stage 1 and 2 (31 cases) had significantly longer survival than patients with nodal involvement or metastatic disease (122 cases) (Fig. 


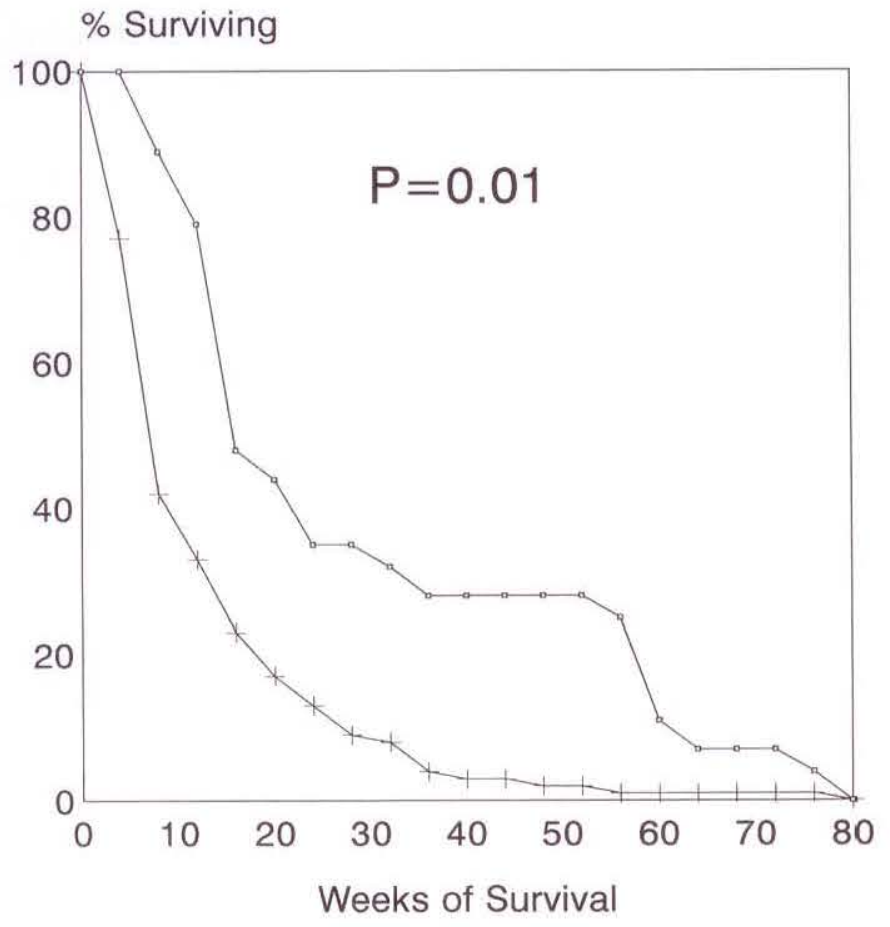

$\rightarrow$ Any RX + No RX

Figure 6) Survival of pancreatic carcinoma patients according to intervention. Intervention (radiotherapeutic or chemotherapeutic in addition to surgery $=T x$ ) $P=0.01$

ure 5). The median survival of stage 2 patients was 11 weeks compared with only five weeks for more advanced disease $(\mathrm{P}=0.001)$.

The number of patients receiving any definitive treatment for cure was extremely small (8\%). Only six of 214 had definitive surgery, which was labelled nonpalliative by the surgeon. The reason for this distribution is unknown. Univariate analysis shows that any extra treatment, whether radiotherapy or chemotherapy, added to the initial surgery, increased survival (Figure 6). However, the numbers are small (only 21 of 214 patients) and much preselection is strongly suspected.

Multivariate regression analysis: Cox regression analysis revealed that only stage and histology remained independent prognostic variables, with sex dis- appearing. Treatment was not used in the model because of the suspected selection.

\section{DISCUSSION}

A population-based study of Manitoba patients with pancreatic carcinoma was analyzed to determine survival and prognostic variables. Stage and histology were found to be independent prognostic variables and should be taken into consideration in any therapeutic trial involving this disease. This is true even though the pathology was not reviewed.

Of great concern is the extremely short survival that was seen in this disease in Manitoba with the relatively few definitive treatment interventions. Most other series report median survivals of six to 22 months $(1,4-6)$, while the median survival for the present group was only six weeks. Even patients with the best prognosis had a median survival of only 10 to 12 weeks, although the tails of the survival curves flatten out after the initial rapid drop off rate. It is possible this totally unselected series based on a tumour registry presents a true picture of a viscious disease. By the time the patient has a consultation with a surgeon, gastroenterologist or oncologist, they have passed one major survival hurdle and thus will survive longer. If we exclude the first six to eight weeks of rapid death to allow 'consultations' the curves resemble other series. Using that maneuvre, median survival of the present patients is nine to 10 months, approximating what is found in the literature. Thus, short survival is likely due to the fact that a sizeable proportion of patients were diagnosed close to death. Clearly, survival could be 'extended' from symptoms, rather than pathological or radiological diagnosis. These are probably the reasons the survival is so short. This study underlines the importance of careful study of prognostic variables in any case control study, and the long known difficulty of historical controls.

\section{REFERENCES}

1. Brennan MF, Kinsella T, Friedman M. Cancer of the pancreas. In: DeVita VT, Hellman S, Rosenberg SA, eds. Cancer Principles and Practices of Oncology, 3rd edn. Philadelphia: Lippincott, 1989:800-1.

2. Allen-Mersh TG, Earlam RJ. Pancreatic cancer in England and Wales: Surgeons look at epidemiology. Ann R Coll Surg Engl 1986;68:154-8.

3. Hill GB, Laidlaw J, Mao Y, et al. Canadian Cancer Statistics. National Cancer Institute of Canada, 1991.

4. Faivre J, Bedenne L, Arveux P, Klepping C. Descriptive epidemiology of cancer of the pancreas. Bull Cancer Paris 1990;77:39-46.

5. Bottger T, Zech J, Weber W, et al. Relevant factors in the prognosis of ductal pancreatic cancer. Acta Chir Scand 1990;156:781-8.

6. Petrek JA, Sandberg WA, Bean PK, et al. Can survival in pancreatic adenocarcinoma be predicted by primary size or stage. Am Surg 1985;51:42-6. 


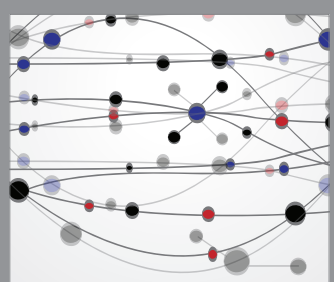

The Scientific World Journal
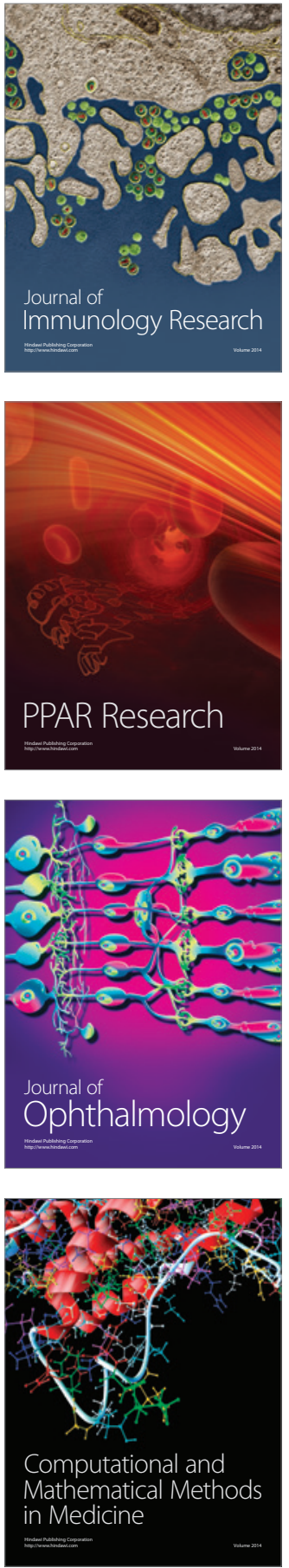

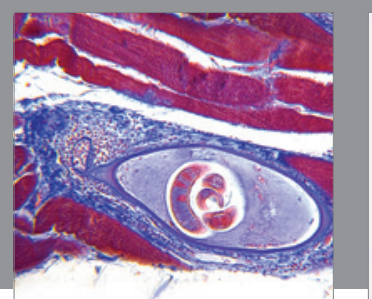

Gastroenterology Research and Practice

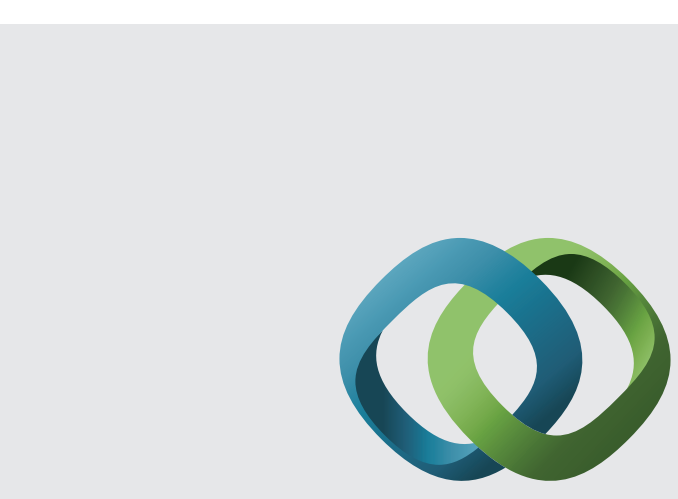

\section{Hindawi}

Submit your manuscripts at

http://www.hindawi.com
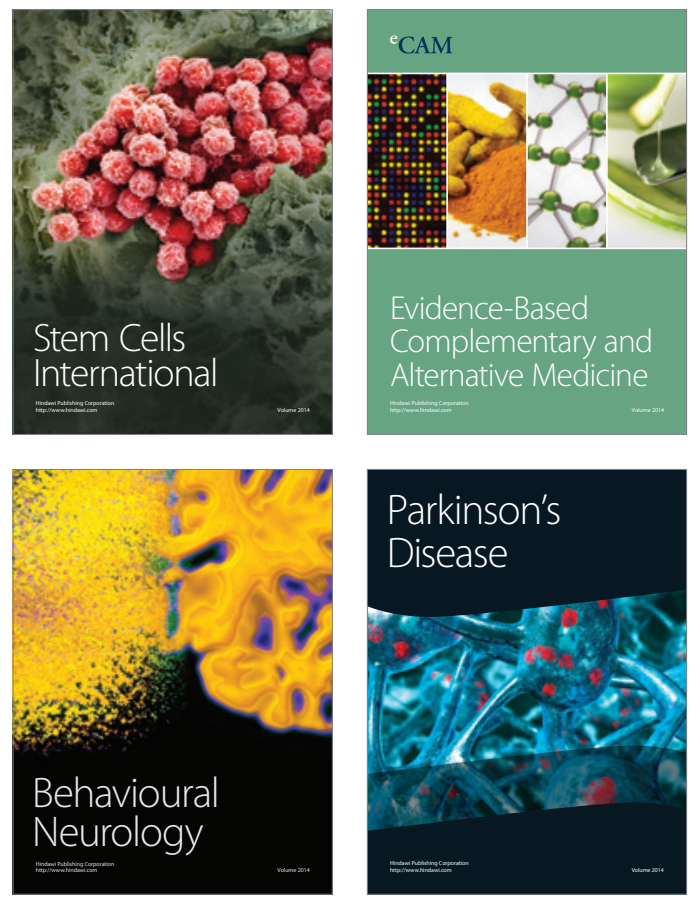
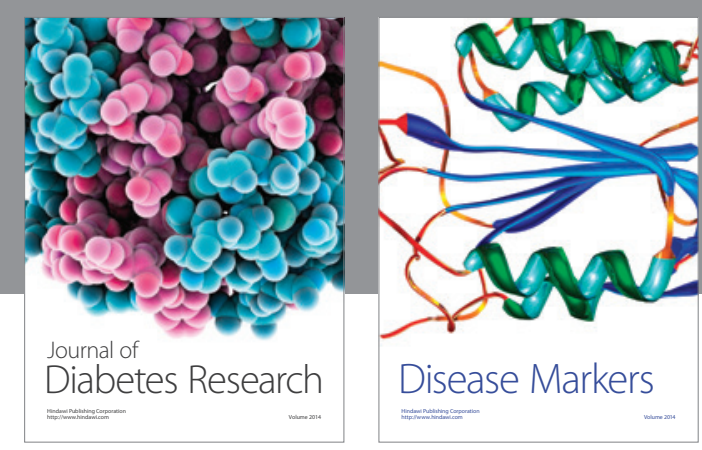

Disease Markers
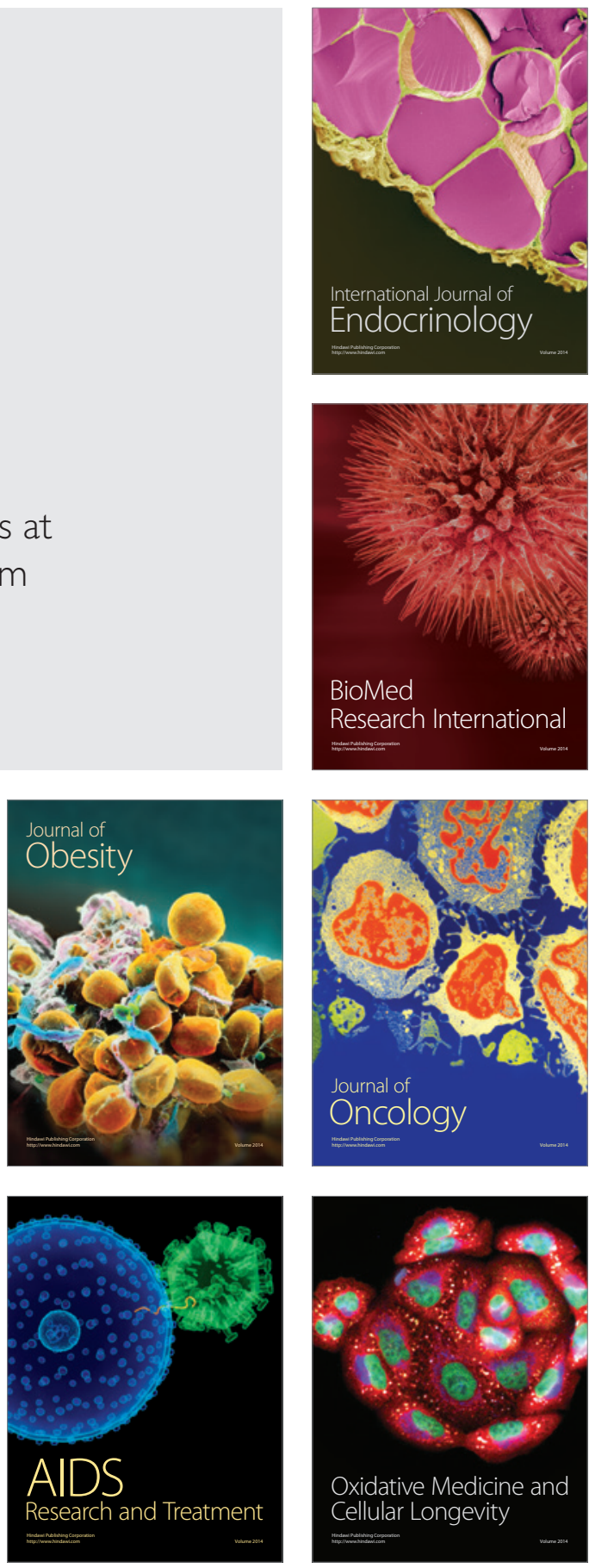